\title{
Twisted tale of the tiger: the case of inappropriate data and deficient science
}

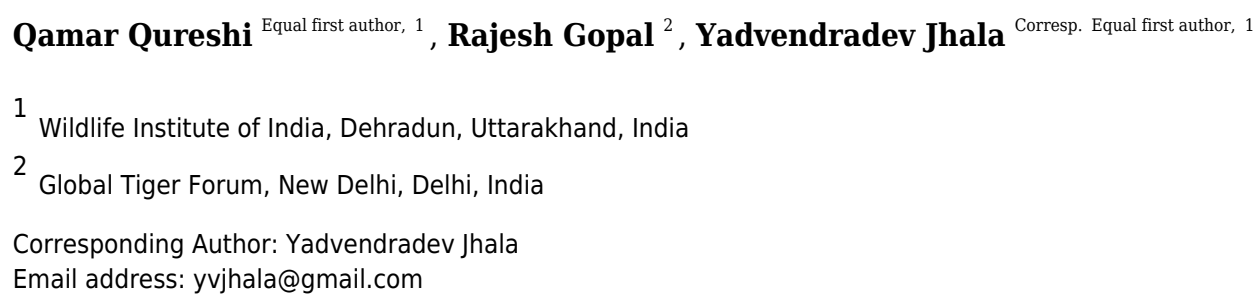

Publications in peer reviewed journals are often looked upon as tenets on which future scientific thought is built. Published information is not always flawless and errors in published research should be expediently reported, preferably by a peer review process. We review a recent publication by Gopalaswamy et al (2015; doi:10.1111/2041-210X.12351) that challenges the use of "double sampling" in large scale animal surveys. Double sampling is often resorted to as an established economical and practical approach for large scale surveys since it calibrates abundance indices against absolute abundance, thereby potentially addressing the statistical shortfalls of indices. Empirical data used by Gopalaswamy et al. (2015) to test their theoretical model, relate to tiger sign and tiger abundance referred to as an Index Calibration experiment (IC-Karanth). These data on tiger abundance and signs should be paired in time and space to qualify as a calibration experiment for double sampling, but original data of IC-Karanth show lags of (up to) several years. Further, data points used in the paper do not match the original sources. We show that by use of inappropriate and incorrect data collected through a faulty experimental design, poor parameterization of their theoretical model, and selectively-picked estimates from literature on detection probability, the inferences of this paper are highly questionable. We highlight how the results of Gopalaswamy et al. were further distorted in popular media. If left unaddressed, Gopalaswamy et al. paper could have serious implications on statistical design of large-scale animal surveys by propagating unreliable inferences. 
1 Twisted tale of the tiger: the case of inappropriate data and deficient science.

2

3 Authors:

\section{Abstract:}

1) Qamar Qureshi, email: qnq@wii.gov.in, Wildlife Institute of India, Chandrabani, Dehradun, India

2) Rajesh Gopal, email : rajeshgopal.sg.gtf@gmail.com, Global Tiger Forum, Jor Baug, New Delhi, India

3) Yadvendradev Jhala*, email: jhalay@wii.gov.in, Wildlife Institute of India, Dehradun, India.

\section{* Corresponding author}

Publications in peer reviewed journals are often looked upon as tenets on which future scientific thought is built. Published information is not always flawless and errors in published research should be expediently reported, preferably by a peer review process. We review a recent publication by Gopalaswamy et al (2015; doi:10.1111/2041-210X.12351) that challenges the use of "double sampling" in large scale animal surveys. Double sampling is often resorted to as an established economical and practical approach for large scale surveys since it calibrates abundance indices against absolute abundance, thereby potentially addressing the statistical shortfalls of indices. Empirical data used by Gopalaswamy et al. (2015) to test their theoretical model, relate to tiger sign and tiger abundance referred to as an Index Calibration experiment (IC-Karanth). These data on tiger abundance and signs should be paired in time and space to qualify as a calibration experiment for double sampling, but original data of IC-Karanth show lags of (up to) several years. Further, data points used in the paper do not match the original sources. We show that by use of inappropriate and incorrect data collected through a faulty experimental design, poor parameterization of their theoretical model, and selectively-picked estimates from literature on detection probability, the inferences of this paper are highly questionable. We highlight how the results of Gopalaswamy et al. were further distorted in popular media. If left unaddressed, Gopalaswamy et al. paper could have serious implications on statistical design of large-scale animal surveys by propagating unreliable inferences. 
34 Scientific method operates by testing competing hypothesis or by choosing between alternate models that best explain observed data. Hypothesis and models that survive repeated testing by careful experimentation are published through rigorous scrutiny by a peer review process, these subsequently become scientific theory (Gauch 2012 ). An incorrect experimental design, inappropriate data collection protocol, and selective data, used for analysis from telemetered Florida panthers (Puma concolor) (Gross 2005) resulted in a peer reviewed publication of habitat use and preference (Maehr \& Cox 1995 ) in Conservation Biology. The results were subsequently used for land use planning and policy (Maehr \& Deason 2002) which resulted in the best panther habitat being lost to developmental projects (Gross 2005). In the ideal world, response to deficiencies in science is best made through a peer review process, since scientists understand the intricacies of the scientific method probably more than others (Parsons \& Wright 2015).

In a recent paper "An examination of index-calibration experiments: counting tigers at macroecological scales" published in the journal Methods of Ecology and Evolution, Gopalaswamy et al (2015a) supposedly demonstrate that as part of their long-term, large-scale data on tiger abundance and index (IC-Karanth) they did not find any relationship between tiger abundance and scat index. They conclude that attempting to use double sampling (Cochran 1977; Eberhardt \& Simmons 1987; Pollock et al. 2002) to establish relationships between any index of abundance and actual abundance is a futile effort. In particular, they claim that the relationship between tiger sign index and tiger abundance published by Jhala et al. (2011a) to be improbable since they could not reproduce it by their data or theoretical model. We review Gopalaswamy et al (2015a) to show that by the use of a) wrong ecological parameters for their theoretical model, b) selectively picked references from literature, c) inappropriate and incorrect data, and d) data not collected in an experimental setup, the inferences drawn by their paper are questionable.

\section{a) Use of inadequate Ecological Parameters:}

The basic premise for index calibration by double sampling is that animal sign intensity or count data should reflect underlying animal abundance. Often due to logistic and economic constraints large scale estimates of abundance are not possible through statistically rigorous methods that 
63 explicitly estimate and correct for detection (e.g. capture-mark-recapture or DISTANCE 64 sampling). Double sampling approach as described initially by Cochran (1977) and applied to wildlife surveys by Eberhardt \& Simmons (1987), allows us to address this limitation by measuring a relatively easy and economically less expensive, but potentially biased index of abundance across all sampling units, while simultaneously estimating detection corrected abundance from within a subset of these sampling units (Conroy \& Carroll 2009, Williams et al. 2002). Subsequently, the potentially biased index is calibrated against the unbiased estimate of abundance or actual abundance using a ratio or regression approach (Skalski et al. 2005). Pollock et al. (2002) recommend double sampling as a sensible large-scale survey design for most 72 species.

To prove their point of view, Gopalaswamy et al (2015a) use detection probability (p) estimates from tiger occupancy studies as a surrogate for detection probability of tiger scat for parameterizing their theoretical model. This $\mathrm{p}$ is the probability of finding (or not finding) tiger sign on a single survey in an area occupied by tigers. Gopalaswamy et. al. (2015) confuse p of occupancy surveys with the probability of finding (or missing) an individual sign (in this case tiger scat) (r). In other words, $p$ represents the number of surveys out of the total surveys that are likely to detect presence of tigers in an occupied site, while $\mathrm{r}$ represents the proportion of tiger signs that are detected (or missed) in a single survey. The two are not the same i.e. $p \neq$ r. For example, a survey that detected nine out of 10 signs present or another that detected one sign out of 10 signs are both considered as having $100 \%$ detection of tiger presence $(p=1)$ for an occupancy survey, but $r$ for each of these surveys is 0.9 and 0.1 respectively. Thus, detection probability ( $p$ ) of occupancy surveys is not informative on per capita detection rates (r) of tiger sign. For estimating $r$ the correct approach would be to use a double blind observer experimental design (Buckland et al. 2010, Nichols et al. 2000), where two observers would walk the same trail some distance apart and record observed tiger scat without communicating with each other. The scats being missed by each of them could then be used to estimate the probability of missing scats entirely.

Also, in occupancy surveys all kinds of signs are often used to detect tigers (pugmarks, 91 scat, scrape, rake marks, direct sightings, vocalization, tiger kills, etc). Karanth et al. (2011a)

92 have used both tiger scat and tiger pugmark to detect tigers in a grid for estimating occupancy. 93 Thus, detection probability of occupancy in these surveys is the compounded probability of 
94 occurrence and detection of both scat and pugmark on a single survey which cannot be teased

95 apart and used as a surrogate for detecting individual scats. From the above it is clear that the use

96 of occupancy detection probability to parameterize detection probability of tiger scat in the

97 theoretical model of Gopalaswamy et al. (2015) is wrong. Typically in a double sample survey

98 the index is measured without an estimate of its detection, by calibrating this potentially biased

99 index against abundance, double sampling elegantly addresses the issue of detection and other

100 sources of variability in the index (Conroy and Carroll 2009).

101

102 b) Selectively picked references.

103 Not only do Gopalswamy et al (2015) use an incorrect detection probability (derived for

104 occupancy studies) in place of a double observer based detection probability for sign intensity for

105 their theoretical model, they were selective in picking low estimates of detection probability with

106 high coefficient of variation (CV) from those available in published literature. The estimates of

107 detection probability p at $1 \mathrm{~km}$ segments (0.17) and its CV (1) from Karanth et al (2011a) were

108 used, claiming that these were the only parameter estimates available. The use of low $\mathrm{p}$ and

109 extraordinarily high CV to suggest that detection of tiger presence for occupancy survey is in

110 general low and highly variable. These parameters play an important role in subsequent

111 derivations in the paper. Gopalswamy et al (2015) have ignored other published estimates of

112 these parameters obtained by sampling large areas and derived by following the same field and

113 analytical protocols. These publications report far higher $\mathrm{p}$ with much smaller CV (Harihar and

114 Pandav (2012), $\mathrm{p}=0.951$ SE 0.05; Barbara-Meyer (2013), $\mathrm{p}=0.65 \mathrm{SE} 0.08$ ). The low $\mathrm{p}$ and high

115 CV reported by Karanth et al (2011a) is likely due to poor design and not a norm in detecting

116 tiger presence. In our experience tigers uses scat, scrape and rakes to advertise their presence and

117 it is highly unlikely that tiger signs will have such a low detectability unless the population is

118 very low, survey design is poor, or data is collected by inexperienced/untrained persons.

119 c) Inappropriate and incorrect data

120 Throughout the paper the authors have used data and parameters related to tigers published by K.

121 Ullas Karanth (a co-author on the paper) and colleagues, which they refer to as Index-calibration

122 experiment - (IC-Karanth). The authors have presented eight paired data points on tiger density

123 and tiger signs (in fact only scats) in figure 5 of the paper. This graph shows no relationship

124 between tiger scat encounter rate and tiger density, considered as an empirical test in support of

PeerJ reviewing PDF | (2018:09:31245:2:0:NEW 4 Jul 2019) 
125 their theoretical model based only on eight data points. On perusal of the references cited in

126 Gopalaswamy et al (2015a), we noticed several irregularities which invalidate the use of these

127 data as a scientific experiment to test this relationship. It is relevant to point out that for

128 calibration of any index with abundance as done in a double sampling experimental approach

129 (Eberhardt \& Simmons 1987), both index and abundance, should be sampled contemporaneously

130 and over the same spatial extent (paired in time and space). In three data points out of eight

131 presented in figure 5 of Gopalaswamy et al. (2015), tiger signs and tiger density were not

132 collected contemporaneously. Tiger density can fluctuate substantially between years (Karanth et

133 al. 2006) and tiger signs have short persistence time. Yet, the data Gopalaswamy et al. (2015) use

134 for their paired experiment has lags of several years (two to seven years) between estimating

135 tiger density and tiger sign (Figure 1). In particular, the data point from Bandipur has a lag of

136 seven years (density estimated in 1999, scat sampling in 2006), data point representing Melghat

137 has a lag of three years (density estimated in 2002, scat sampling done in 2005) and data point

138 from Pench Maharashtra has a lag of two years (density estimated in 2002, scat sampling done in

139 2004) (Karanth \& Nichols 2000, 2002; Karanth et al. 2004; Karanth \& Kumar 2005; Andheria

140 2006, see supplementary material for relevant sections of these publications). The authors do

141 have concurrent density estimates from one of these sites (Bandipur) with smaller variance

142 (Gopalswamy et al 2012), but curiously have not chosen to use or refer to this. At one data point

143 (Tadoba), an extreme outlier at right corner of figure 5 of Gopalaswamy et al (2015a) (Figure 1),

144 the data on scat encounters does not match the original source (scat encounter rate $3.6 / 10 \mathrm{~km}$ as

145 given in figure 5 of Goplaswamy et al (2015) vs. 1.99/10 km as given in the original source

146 (Karanth \& Kumar 2005; but addressed this by mentioning that the original reference was

147 incorrect in a corrigendum to the original paper Gopalaswamy et al (2015b)). Yet two data points

148 (Melghat and Pench Maharashtra) continue to differ in their Fig 5 (Gopalaswamy et al (2015a)

149 from the cited references in the corrigendum Gopalaswamy et al (2015b).

150 Methods for recording scat encounter rates differed between source reference sites used

151 for IC-Karanth. Andheria (2006) removed all scats encountered on the first sample and

152 discarded them from data analysis, a practice which is not uniformly followed for recording

153 tiger scat encounter rates in other studies. For studies referenced for IC-Karanth, camera

154 trap sampling was done in small areas within larger protected areas for estimating tiger

155 density, whereas tiger scats were collected for studying tiger diet (Karanth \& Nichols 2000, 
156 2002; Karanth et al. 2004; Karanth \& Kumar 2005; Andheria 2006) possibly

157 opportunistically from the entire reserve. Any intent of calibrating these tiger scat data to

158 tiger density obtained through camera trap sampling is not mentioned in any of the original

159 sources. In the original studies cited by Gopalaswamy et al. (2015) referred to as IC-

160 Karanth experiment, there seems to be no intent of designing an experiment to evaluate the

161 relationship between tiger sign encounter rate and tiger density, the sources are unclear if

162 the scat sampling was done within the same spatial extent as the camera trap survey for

163 estimating tiger density. The basic premise of a double sampling experimental approach,

164 wherein data from both samples (index and density) need to be paired in time and space is

165 violated in the field experiment (IC-Karanth) of Goplaswamy et al (2015) invalidating their

166 conclusions.

167 [Figure 1. Here]

168

169

170

171

172

d) Variability in tiger capture probability and density estimates from camera trap capturemark-recapture.

173 As with occupancy detection probability, Gopalaswamy et al. (2015) restrict themselves entirely

174 to 11 estimates of tiger density published by Karanth et al (2004) for their models. On multiple

175 occasions they point out the highly variable capture probability $\mathrm{p}$ and variance associated with

176 tiger density estimates. In fact, in light of the large number of published tiger density estimates

177 with higher precision (e.g. 21 estimates in Jhala et al 2011a), these authors should have

178 considered Karanth et al (2004) estimates as particularly lacking in precision. When, estimates

179 with large sampling errors are used to guide development of theoretical models it would be

180 difficult to deduce any relationship between tiger signs and tiger density. Poor precision of tiger

181 density estimates in Karanth et al (2004) were likely due to poor sampling design and not

182 something that is inherent in tiger population estimation, e.g. for data presented in Karanth et al

183 (2004) CV of tiger density increases with increase in sampled area and $p$ decreases with the

184 sampled area ( $\mathrm{r}=0.4$, and -0.63 respectively). Overstating the case of sampling uncertainty can

185 only do harm to the development and adoption of sound and practical methods. 
187 e) Repeating non peer-reviewed literature to advance unsubstantiated claims

188 Gopalaswamy et al. (2015) claim that the methods followed by Jhala et al. (2011a) have resulted

189 in "improbable estimates of $49 \%$ increase in tiger density over 4 years". Gopalaswamy et al

190 (2015a) do not explain how they arrived at the figure of $49 \%$ increase, they cite a letter to

191 Science, commenting on a news article (Karanth et al 2011b), but they have not explained the

$19249 \%$ increase in tiger abundance in this letter as well (Jhala et al. 2011c). The fact is that in 2006

193 India's mean tiger population was estimated at about 1400 while in 2010 the estimate was about

1941700 but included estimates from some new areas like Sundarbans that were not assessed in

195 2006. Comparing tiger numbers between common areas sampled in 2006 and 2010 an increase

196 of $17.6 \%$ was estimated in four years, or about 4\% per year; which is very probable for large

197 carnivores. It is inexplicable to us how Gopalaswamy et al (2015a) arrived at a 49\% increase in

198 abundance or why they continue to perpetuate this obviously erroneous inference.

\section{f) Propaganda that is not consistent with facts}

202 The paper of Gopalaswamy et al (2015a) is, as the title suggests, about "index calibration

203 experiment" especially referring to estimation of tiger abundance. To this extent the reference to

204 Jhala et al (2011a) that demonstrates a strong relation between tiger sign index and tiger

205 abundance as IC-Jhala and several publications of U. Karanth as IC-Karanth is relevant.

206 Gopalaswamy et al. (2015a) seem to have gone through the methods employed for estimating the

207 status of tigers in India thoroughly (Jhala et al. 2008, 2011b, and 2015), since they have

208 meticulously computed parameters from these reports for their paper. K. U. Karanth is also an

209 author on several chapters in Jhala et al (2015). They should know that national tiger status

210 assessments (Jhala et al 2008, 2010, 2015) were never based on tiger sign index alone. Tiger sign

211 index was one amongst the many ecologically important covariates that included human

212 footprint, prey abundance and landscape characteristics, that were used for modeling tiger

213 density. Yet, the blog of the journal Methods in Ecology and Evolution titled "flawed method

214 puts tiger rise in doubt " states "amongst recent studies thought to be based on this method is

215 India's national tiger survey " (Grives 2015) which the blog then discredits as being inaccurate

216 based on conclusions of Gopalaswamy et al. (2015a). The fact is India's national tiger survey of 
2172014 (Jhala et al. 2015) used spatially explicit capture-recapture (SECR) in a joint likelihood

218 based framework (Efford 2012) with covariates of prey abundance, tiger sign intensity, habitat

219 characteristics, and human footprint. The SECR and Joint likelihood analysis are a recent

220 development (Brochers \& Efford 2008, Efford 2011) and therefore could not have been used for

221 earlier national tiger assessments which used general linear models (Jhala et al 2008, 2011b).

222 The misleading reports that subsequently followed in the media had forgotten that the MEE

223 paper by Gopalaswamy et al. (2015a) is a debate on index calibration using double sampling

224 approach (Eberhardt \& Simmons 1987) with simple linear regression and not about national tiger

225 status assessment. The 2014 national tiger status assessment was based on photo-captures of

2261506 individual tigers, capture-histories of these were subsequently modeled in SECR with

227 covariates of prey, habitat and human impacts to estimate 2226 (SE range 1945 to 2491, $>1.5$

228 year old) tigers from across India (Jhala et al 2015). This amounts to $68 \%$ of the total tiger

229 population being photo-captured and 77\% (1722; 95\% CI 1573 to 2221 tigers) of the total tiger

230 population being estimated by capture-mark-recapture without any extrapolation using

231 covariates/indices. By muddling index calibration with the national tiger survey in the paper

232 (Gopalaswamy et al. 2015) and in all subsequent press releases and interviews Dr. Ullas Karanth

233 and coauthors incorrectly use the Gopalaswamy et al. (2015a) paper results (which are

234 themselves highly questionable) to discredit the national tiger survey results as being inaccurate

235 (Bagla 2016, Chauhan 2015, Croke 2015, Grives 2015, Karanth 2015, 2016, Rohit 2015, Sinha

236 and Bhattacharyal 2015, Vaughn 2015, and Vishnoi 2015) and mislead the readers.

237 Peer reviewed publications form the basis for advancement of science and are often cited and

238 used as a basis from which to move ahead. Indeed, the Gopalaswamy et al. (2015a,b) paper has

239 been subsequently cited in papers addressing methodological reviews, advances and policies

240 (Darimont et al 2018, Hayward et al. 2015), abundance estimation papers (Broekhuis and

241 Goplaswamy 2016, Caley 2015, Elliot and Gopalaswamy 2017, Falcy et al 2016, Mahard et al

242 2016) and in some Masters and Ph.D. thesis (Walker 2016, Moorcroft 2017). Published scientific

243 literature can have errors, these can occur through negligence of scientists or deliberate

244 misleading of science (Macilwain 2014), and can pass the peer review process due to ignorance,

245 poor diligence, or vested interest (Parsons \& Wright 2015). Mistakes in published science

246 should be corrected expediently, as these are detrimental to the scientific progress in the specific

247 field and propagate a wrong basis for further research. In our opinion, Gopalaswamy et al. 
248 (2015a, b) results are misleading, due to inappropriate scientific process and data, and have

249 therefore not contributed to the wider debate on the usefulness of double sampling (Eberhardt \&

250 Simmons 1987; Pollock et al. 2002) for large-scale animal surveys.

251 We stress that landscape scale surveys need to be a blend of robust statistical design and analysis

252 that are pragmatic (economic and logistically possible) to achieve. The national tiger surveys of

253 India (Jhala et al. 2008, 2011, 2015) have striven to keep pace with modern advancement in

254 animal abundance techniques and analysis and have used robust statistical tools available within

255 the constraints of large-scale data coverage, resources, and timeframe. The concept and

256 philosophy of double sampling (Cochran 1977) forms the basis for modern statistical and

257 analytical approaches that infer relationships between actual abundance and counts, indices, and

258 covariates. The family of general linear models, generalized additive models (Zuur et al. 2009),

259 joint likelihood (Conroy et al. 2008), SECR with habitat covariates (Efford and Fewster 2013),

260 and SECR joint likelihood (Chandler and Clark 2014) take the relationship between an

261 index/covariates and absolute abundance to various levels of analytical complexity. There seems

262 to be some agreement on the best analytical approach to use for landscape scale abundance

263 estimation of tigers between Gopalaswamy et al. (2015a) and us (Jhala et al. 2015).

264 Gopalaswamy et al. (2015a) recommend using the joint likelihood approach, while the tiger

265 status assessment for India for the year 2014 used spatially explicit joint likelihood with camera-

266 trap data of tigers, and covariates of tiger sign index, prey abundance and human footprint

267 indices (Jhala et al. 2015). Yet, we stress the relevance and importance of first exploring

268 relationships of abundance with indices and covariates, based on sound ecological logic before

269 attempting complex statistical analysis, and refrain from putting the proverbial cart (statistical)

270 before the horse (ecology) (Krebs 1989).

271

272

273

Acknowledgements:

274

275 We acknowledge Rashid Raza for painstakingly retrieving old reports to verify data used for IC-

276 Karanth and helping draft this paper. We thank S. Dutta, S. Bist, Bipin C., and V. Kolipakam for 277 their comments on the manuscript. 
279 References:

280 Andheria, A. P., Assessment of diet and abundance of large carnivores from field surveys of 281 scats. Master's thesis, Manipal University, 2006.

282

283 Bagla, P., Are India's tiger numbers inflated? The Economic Times, Jul. 24, 2016,

284 http://economictimes.indiatimes.com/news/science/are-indias-tiger-numbers-

285 inflated/articleshow/53361321.cms

286

287 Barber-Meyer, S. M., Jnawali, S. R., Karki, J. B., Khanal, P., Lohani, S., Long, B., et al., 288 Influence of prey depletion and human disturbance on tiger occupancy in Nepal. Journal of 289 Zoology, 2013, 289, 1, 10-18.

290

291 Borchers, D. L. and Efford, M. G., Spatially explicit maximum likelihood methods for capture292 recapture studies. Biometrics, 2008, 64, 377-385.

293

294 Broekhuis F, and Gopalaswamy A. M., Counting Cats: Spatially Explicit Population Estimates of 295 Cheetah (Acinonyx jubatus) Using Unstructured Sampling Data. PLoS ONE, 2016, 11, 5 , 296 e0153875. https://doi.org/10.1371/journal.pone.0153875

297

298

299

Buckland, S. T., Laake, J. K., and Borchers, D. L., Double-observer line transect methods: levels of independence. Biometry, 2010, 66,169-177.

300

301

Caley, P., Sampling designs for effective monitoring and evaluation of research questions relating to cats. In 2015 National Feral Cat Management Workshop, 2015, p. 61.

303

304

Chandler, R. B. and Clark, J. D., Spatially explicit integrated population models. Methods in 305 Ecology and Evolution 2014, 5, 1351-1360

306

307

Chauhan, C. Scientists to file rebuttal to Oxford study. 2015, Hindustan Times, Bhopal, 308 https://www.highbeam.com/doc/1P3-3603449221.html 
310 Cochran, W.G., Sampling Techniques, 3rd edn. John Wiley \& Sons, New York, USA, 1977.

311

312 Croke, V., What's got the king of counting tigers growling. 2015.

313 http://thewildlife.wbur.org/2015/05/14/whats-got-the-king-of-counting-tigers-growling.

314

315 Conroy, M. J., Runge, J. P., Barker, R. J., Schofield, M. R. \& Fonnesbeck, C. J., Efficient

316 estimation of abundance for patchily distributed populations via two-phase, adaptive

317 sampling. Ecology, 2008, 89, 3362-3370.

318

319 Darimont, C. T., Paquet, P. C., Treves, A., Kyle, K. A., and Chapron, G., Political populations of 320 large carnivores. Cons. Biol., 2018, 32, 747-749.

321

322 Eberhardt, L. L. and Simmons, M. A., Calibrating population indices by double sampling. J.

323 Wildl. Manag., 1987, 51, 665-675.

324

325 Efford, M. G., secr-spatially explicit capture-recapture in R. http://

326 www.otago.ac.nz/density/pdfs/secr-overview\%202.3.0.pdf., 2011.

327

328 Efford, M. G. and Fewster, R. M., Estimating population size by spatially explicit capture329 recapture. Oikos, 2013, 122, 918-928.

331 Elliot, N. B. and Gopalaswamy, A. M., Toward accurate and precise estimates of lion density. 332 Conservation Biology, 2017, doi:10.1111/cobi.12878

333

334 Falcy, M. R., McCormick, J. L., and Miller, S. A., Proxies in Practice: Calibration and 335 Validation of Multiple Indices of Animal Abundance. Journal of Fish and Wildlife

336 Management, 2016, 7, 1, 117-128. doi: http://dx.doi.org/10.3996/092015-JFWM-090 337

338 Gauch, H. G. Jr., The scientific method in brief. Cambridge University Press, Cambridge, UK, 3392012. 
341 Gopalaswamy, A. M., Royle, J. A., Delampady, M., Nichols, J. D., Karanth, K. U., and

342 Macdonald, D. W., Density estimation in tiger populations: combining information for strong 343 inference. Ecology, 2012, 93, 7, 1741-1751.

344

345 Gopalaswamy, A. M., Delampady, M., Karanth, K. U., Kumar, N. S., and Macdonald, D. W., An 346 examination of index-calibration experiments: counting tigers at macroecological scales. Meth.

347 Ecol. \& Evol., 2015, 6, 1055-1066, doi: 10.1111/2041-210X.12351

348

349 Gopalaswamy, A. M., Delampady, M., Karanth, K. U., Kumar, N. S, and Macdonald, D. W.,

350 Corrigendum. Meth. Ecol. \& Evol., 2015, 6, 1067-1068, doi:10.1111/204-210X.12400.

351

352 Grives, C., Flawed method puts tiger rise in doubt. Meth. Ecol. \& Evol., Official Blog, 2015,

353 https://methodsblog.wordpress.com/2015/02/23/flawed-method-puts-tiger-rise-in-doubt/

354

355

Gross, L., Why not the best? How science failed the Florida panther. PLoS Biol 2005, 3, 9, e333.

356

357

Harihar, A. and Pandav, B., Influence of Connectivity, Wild Prey and Disturbance on Occupancy

358

of Tigers in the Human-Dominated Western Terai Arc Landscape. PLoS ONE, 2012, 7, 7,

359

e40105, doi:10.1371/journal.pone.0040105.

360

361

Hayward, M. W., Boitani, L., Burrows, N. D., Funston, P. J., Karanth, K. U., MacKenzie, D. I.,

362

Pollock, K. H. and Yarnell, R. W., FORUM: Ecologists need robust survey designs, sampling

363

and analytical methods. J. Appl. Ecol., 2015, 52, 286-290, doi:10.1111/1365-2664.12408.

364

365 Jhala, Y., Qureshi, Q. and Gopal, R., Status of tigers, copredators and prey in India 2006. (Eds).

366 National Tiger Conservation Authority, New Delhi and Wildlife Institute of India, Dehradun.

367 2008, TR 08/001 pp. 164.

368

369 Jhala, Y., Qureshi, Q., and Gopal, R., Can the abundance of tigers be assessed from their signs?

370 J. Appl. Ecol., 2011a, 48, 1, 14-24.

371

PeerJ reviewing PDF | (2018:09:31245:2:0:NEW 4 Jul 2019) 
372 Jhala, Y., Qureshi, Q. and Gopal, R., Status of tigers, copredators and prey in India 2010. (Eds).

373 National Tiger Conservation Authority, New Delhi and Wildlife Institute of India, Dehradun,

374 2011b, TR 2011/003, pp. 302.

375

376 Jhala, Y. V., Qureshi, Q. and Gopal, R., Counting India's wild tigers reliably: a response,

377 Science, $2011 \mathrm{c}$.

378

379

Jhala, Y., Qureshi, Q. and Gopal, R., Status of tigers, copredators and prey in India 2015. (Eds).

380

National Tiger Conservation Authority, New Delhi and Wildlife Institute of India, Dehradun,

381

2015, TR 2015/021, pp, 456.

382

383 Karanth, K. U., Nichols, J. D., Kumar, N. S. and Hines, J. E., Assessing tiger population

384 dynamics using photographic capture-recapture sampling. Ecology, 2006, 87, 2925-2937,

385 doi:10.1890/0012-9658(2006)87[2925:ATPDUP]2.0.CO;2

386

387 Karanth, K. U., Gopalaswamy, A. M., Kumar, N. S., Vaidyanathan, S., Nichols, J. D. and

388 MacKenzie, D. I., Monitoring carnivore populations at the landscape scale: occupancy modelling

389 of tigers from sign surveys. J. Appl. Ecol., 2011a, 48, 1048-1056.

390

391 Karanth, K. U., Gopalaswamy, A. M., Kumar, N. S., Delampady, M., Nichols,J. D.,

392 Seidensticker, J., Noon, B. R. \& Pimm, S. L., Counting India’s Wild Tigers Reliably. Science, $3932011 b, 332,791$.

394

395

396 Karanth, K. U. and Kumar, N. S., Distribution and Dynamics of Tiger and Prey Populations in

397 Maharashtra, India, Final Technical Report, Centre for Wildlife Studies, Bangalore, 2005.

398

399 Karanth, K. U. and Nichols, J. D., Ecological Status and Conservation of Tigers in India. Centre

400 for Wildlife Studies, Bangalore, India, 2000.

401 
402 Karanth, K. U. and Nichols, J. D, Monitoring Tigers and their Prey: A Manual for Researchers, 403 Managers and Conservationists in Tropical Asia, Centre for Wildlife Studies, Bangalore, 2002. 404

405

406 407

408

409

410

411

412

413

414

415

416

417

418

419

420

421

422 423 424

425

426

427

428

429 430

Karanth, K. U., Nichols, J. D., Kumar, N. S., Link, W. A. and Hines, J. E., Tigers and their prey: predicting carnivore densities from prey abundance. PNAS United States of America, 2004, 101, 4854.

Karanth, U. K., Why India's tiger census is misleading. The Guardian, 2015.

https://www.theguardian.com/environment/2015/may/20/why-indias-tiger-census-is-misleading.

Karanth, U. K., The trouble with tiger numbers. Scientific American, 2016, 315, 1.

https://www.scientificamerican.com/article/the-trouble-with-tiger-numbers/

Krebs, C. J., Ecological methodology. No. QH541. 15. S72. K74 1999. New York: Harper \& Row, 1989.

Macilwain, C., Beware of backroom deals in the name of science. World View. Nature, 2014, 508:289.

Maehr, D. S, and Cox, J. A., Landscape features and panthers in Florida. Cons. Biol. 1995, 9, $1008-1019$.

Maehr, D. S, and Deason, J. P., Wide-ranging carnivores and development permits: Constructing a multi-scale model to evaluate impacts on the Florida panther. Clean Technol. Environ. Policy, 2002, 3,398-406.

Mahard, T. J., Litvaitis, J. A., Tate, P., Reed, G. C. and Broman, D. J. A., An evaluation of hunter surveys to monitor relative abundance of bobcats. Wildl. Soc. Bull., 2016, 40, 224-232. doi:10.1002/wsb.642

Martinson, B. C., Anderson, M. S., and de Vries, R., Scientists behaving badly, Nature, 2005, $435,737-738$. 
432 Moorcroft, E. A., Paws for thought: Assessing the efficacy of monitoring techniques for rare and 433 elusive species. Ph.D. dissertation, University College London. UK. 2017, pp, 226.

434 https://pdfs.semanticscholar.org/16bd/eb96a5fdb8d59e6d8f5381ae69f433deffbc.pdf 435

436 Nichols, J. D., Hines, J. E., Sauer, J. R., Fallon, F. W., Fallon, J. E., and Heglund, P. J., A 437 double-observer approach for estimating detection probability and abundance from point 438 counts. The Auk, 2000, 117, 2, 393-408.

Parsons E. C. M. and Wright A. J., The good, the bad and the ugly science: examples from the 440 marine science arena. Frontiers in Marine Science, 2015, 2, 33, DOI=10.3389/fmars.2015.00033.

442 443 444 445

Pollock, K. H., Nichols, J. D., Simons, T. R., Farnsworth, G. L., Bailey, L. L. and Sauer, J. R., Large scale wildlife monitoring studies: statistical methods for design and analysis. Environmetrics, 2002, 13, 2,105-119.

Rohit, B. R., We can double tiger numbers if there is political will: Karanth. Times of India. 2015, http://timesofindia.indiatimes.com/city/bengaluru/We-can-double-tiger-numbers-if-thereis-political-will-Karanth/articleshow/45959006.cms

Sinha, K. and Bhattacharyal, A., India's tiger census method flawed, says Oxford study. Times of India. 2015, http://timesofindia.indiatimes.com/home/environment/flora-fauna/Indias-tigercensus-method-flawed-says-Oxford-study/articleshow/46353339.cms-

Skalski J. R., Ryding, K. E. and Millspaugh, J. J., Wildlife demography: analysis of sex, age, and count data, Elsevier Academic Press, Burlington, MA, USA, 2005.

Tingley, M. W., Wilkerson, R. L., Howell, C. A., and Siegel, R. B., An integrated occupancy and space-use model to predict abundance of imperfectly detected, territorial vertebrates. Meth. Ecol. \& Evol. 2015, 7, 508-517. doi: 10.1111/2041-210X.12500 
461 Varma, A. K., An open approach must for tiger census. Deccan Herald. 2015,

462 http://www.deccanherald.com/content/464950/an-open-approach-must-tiger.html

463

464 Vaughan, A., India's tiger success story may be based on inaccurate census, says study. The

465 Guardian, 2015, https://www.theguardian.com/environment/2015/feb/24/indias-tiger-success-

466 story-may-be-based-on-inaccurate-census-says-study

467

468 Vishnoi, A., Government seeks withdrawal of research paper questioning tiger population, 469 Economic Times, 2015,

470 http://economictimes.indiatimes.com/news/economy/policy/government-seeks-withdrawal-of-

471 research-paper-questioning-tiger-population/articleshow/47021123.cms

472

473 Walker, T. A., Testing camera trap density estimates from the spatial capture model and

474 calibrated capture rate indices against Kangaroo Rat (Dipodomys spp.) live trapping

475 data, Master's Thesis, San Jose State University, CA, USA,

476 2016. http://scholarworks.sjsu.edu/etd theses/4742

477

478 Williams, B. K., Nichols, J. D., and M. J. Conroy, Analysis and management of animal

479 populations. Academic Press, San Diego, CA, USA, 2001.

480 
482 Figure 1. Recreation of figure 5 from Gopalaswamy et al. (2015) highlighting the data 483 discrepancies in the index-calibration experiment. The names of tiger reserves from central 484 Indian landscape and Western Ghat landscape, where sampling was done are mentioned. MR 485 refers to the State of Maharashtra, and MP refers to the State of Madhya Pradesh. 486 
Figure $\mathbf{1}$ (on next page)

Recreation of figure 5 from Gopalaswamy et al. (2015) highlighting the data discrepancies in the index-calibration experiment. The names of tiger reserves from central Indian landscape and Western Ghat landscape, where sampling was done are mentioned. MR

refers to the State of Maharashtra, and MP refers to the State of Madhya Pradesh. 


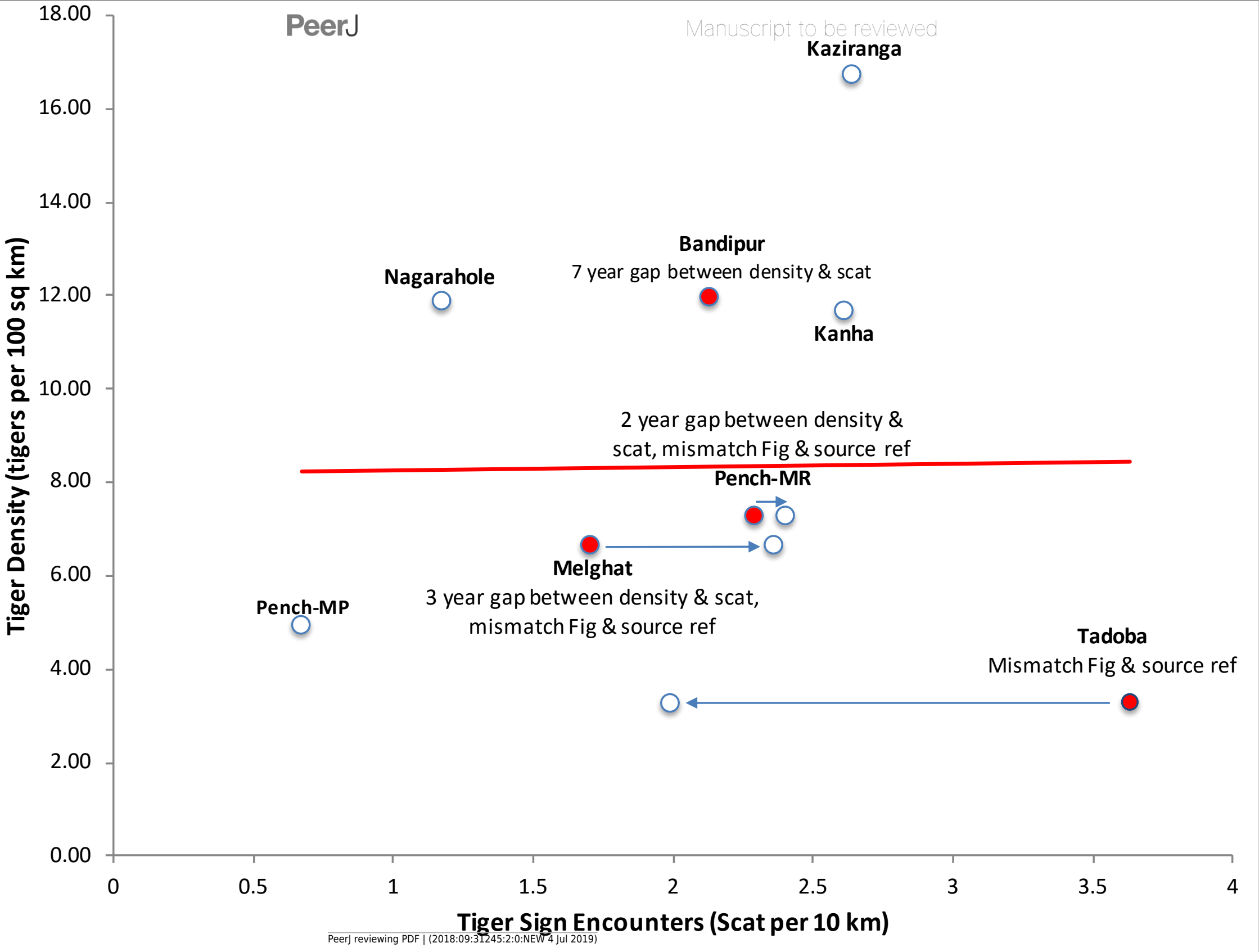

